\title{
Study on the Price Types of Construction Contracts for Construction Works
}

\author{
Hao Zhang ${ }^{a}$, Chengbin Liu ${ }^{*}, \mathrm{~b}$ and Xiuqing Gao ${ }^{\mathrm{c}}$ \\ Department of Hydraulic and Architectural Engineering, Beijing Vocational College of Agriculture, \\ Beijing 102442, China. \\ azhanghao731104@sina.com, , , bliuchengbin1979@163.com, '63262@bvca.edu.cn
}

Keywords: Price types of contracts, unit price contracts, lump sum contracts.

\begin{abstract}
When the project is built, the units undertaking projects and the unit in charge of construction will sign the construction contract. In this paper, the dialectical relationship between "fixed" and "adjustable" of contract prices, the differences between lump sum contracts and unit price contracts, as well as the contractual binding of unit prices in unit price contracts are discussed from the perspective of the price types of contracts. Finally, the application of the price types of contracts are studied from the perspectives of selecting the price types of contracts, avoiding unbalanced bids, and analyzing the scope of pricing, so as to provide the basis for the reasonable price of the bidding and tendering.
\end{abstract}

\section{Introduction}

Article 12.1 of the Model Text for Construction Contract for Construction Works (GF-2013-0201) (hereinafter referred to as "the 2013 Construction Contract") stipulates that the price types of contracts include unit price contracts, lump sum contracts, and other types of contracts, and other types of contracts include cost-plus-incentive fee contracts. As defined in the 2013Construction Contract, a unit price contract is a contract under which unit prices are relatively fixed and not subject to adjustment only within the agreed scope, and a lump sum contract is a contract under which the total contract price is not subject to adjustment only within the agreed scope[1].

Before the issue of the 2013 Construction Contract, contracts were divided into fixed-price contracts, adjustable price contracts, and cost-plus-incentive fee contracts as stipulated in the 1999 Model Text for Construction Contract.

Article 7.1.3 of the Code of Pricing Based on the Bill of Quantities of Construction Works(GB50500-2013) (hereinafter referred to as "the 2013 Code of Pricing”) provides that unit price contracts shall be used for workpriced based on the bill of quantities, and that lump sum contracts may be used for construction works with small scales of construction, low levels of technical difficulty, and whose construction drawing design has been reviewed and approved. A unit price contract mentioned in the Code of Pricingis a contract under which unit prices are fixed and not subject to adjustment under the agreed conditions, and a lump sum contract mentioned means a fixed lump-sum contract[2].

\section{Analysis and Discussion of Cases}

\section{"Fixed" and “Adjustable” in the Price Types of Contracts.}

Fixed prices are not subject to identification. Case: A developer and a constructor, when signing a General Construction Contract, agree that the fixed total contract price established based on the bill of quantities is fixed based on the construction drawings, and that progress payments are paid for $70 \%$ of actual quantities. However, in the construction process, prices of materials and labor rise sharply. When $90 \%$ of work has been completed, the contractor says that the contract price has been lower than the project cost and requests the employer to adjust the contract price on the basis of fairness. The employer refuses to adjust the contract price, and the contractor brings an action. 
Analysis: Article 22 of the Explanations of the Supreme People's Court as to the Legal Issues Applicable to the Trials of Disputes over the Construction Contracts for Construction Works provides that, where the parties agree to settle project payments on a fixed price basis, either party's request for identification of the project cost will not be supported. In accordance with the above stipulation that fixed prices are not subject to identification, the contractor's request for an adjustment in the contract price is not supported since a fixed lump-sum contract is signed and the total price is fixed based on the construction drawings in the case.

Fixed prices are not subject to identification on the premise of a definite "period", namely a stipulated construction period. Fixed prices are subject to identification where the construction period is exceeded due to the employer. Fixed prices are not subject to identification also on the premise of a definite "scope"; in other words, changes beyond the scope of fixed prices are subject to identification. A fixed-price contract shall stipulate that whether fixed prices are fixed based on the bill of quantities or on the drawings. Otherwise, when a contractor completes the workindicated on the drawings but not listed in the bill of quantities, the stipulation that fixed prices are not subject to identification does not apply, and the judicial department will make an identification and request the employer to pay for such portion of work. Therefore, an employer shall stipulate that fixed prices are adopted for all workindicated on the drawings when signing a fixed price contract[3].

Whether the prices of fixed-price contracts are definitely not subject to adjustment. Case: The employer and contractor of a project sign a fixed lump sum contract at a total project cost of over RMB sixty million. In the construction process, the steel prices at the location of the project rise by $30 \% \sim 50 \%$. The steel consumption of the project is over 7,000 tons, and the sharp rises in steel prices cause a loss of as much as over RMB four million. The contractor considers such rises unforeseeable by it when submitting the bid, and that the employer shall compensate the loss. However, the employer considers that the contract is a "fixed lump sum" one, and that such rises in material prices belong to commercial risks that the contractor shall assume. Therefore, the employer refuses to adjust the contract price for that reason.

Analysis: In the above case, the contractor requests an adjustment in the contract price on the grounds that the contract price is lower than the project cost. Let us think about a circumstance where the project cost undergoes a tremendous change so as to far exceed the contract price, which would be obviously unfair for the contractor. Is it reasonable to say that "the price of a fixed lump sum contract is not subject to adjustment"?

Article 26 of the Interpretations II of the Supreme People's Court as to Several Issues Applicable to the Contract Law of the People's Republic of China (Fashi [2009] No.5) provides that, in case of any major changes, after the concluding of a contract, that are unforeseeable at the signing of the contract by the parties and not attributable to force majeure and do not belong to commercial risks, and further performance of the contract would be obviously unfair to a party of the contract or could not achieve the purpose of the contract, the people's court shall decide based on fairness and the reality of the case whether to modify or terminate the contract if such party requests the people's court to modify or terminate the contract.

According to this provision, as long as major changes occur, namely the significant difference of the realities from the circumstances under which an adjustable price contract or a fixed price contract is signed, and further performance of the contract could not achieve the purpose of the contract and would be obviously unfair, the contract may be modified, and the contract price may be adjusted appropriately. This principle is referred to as the principle of change of circumstances in the Contract Law.

Generally speaking, the risk of increases in material prices of smaller than $5 \%$ is to be borne by the contractor; the risk of increases in material prices of greater than $5 \%$ is to be borne by the parties, and the principle of fairness can be reflected only by distribution of the risk between the parties. Price fluctuations of smaller than $10 \%$ belong to commercial risks, and price fluctuations of greater than $10 \%$ do not belong to commercial risks. For example, it would be unfair not to adjust the contract price in case of price fluctuations of $30 \% \sim 50 \%$. In the case of change of circumstances, the price of a fixed price contract may also be adjusted appropriately. 
Is it necessary to list adjustable price contracts as a price type contract? Question: Since the price of a fixed price contract is not absolutely non-adjustable, how the meaning of "fixed" is reflected?

Analysis: Article 6.2.2 of the 2013 Code of Pricing provides that the comprehensive unit price shall cover the scope and cost of risks to be borne by the bidder as stipulated in the bidding documents. Where the bidding documents fail to make such stipulation, the bid inviter shall be reminded to do so. Article 3.4.1 provides that for the contracting of construction works, the risks on which pricing is based shall be defined in the bidding documents and the contract, and such risks may not be unlimited or all risks.

The above stipulation indicates that the unit prices or amounts in contracts cannot be absolutely fixed and shall cover certain risks. In order to avoid disputes, the parties to a contract shall agree on how to distribute risks such as price fluctuations when signing the contract. The contract price may be adjusted against the scope of risks that can be agreed on based on industry practices, such as 3\% by which the increases in steel and cement prices exceed their bid prices and $5 \%$ by which the increases in other material prices exceed their bid prices. Therefore, the price of a fixed-price contract is also adjustable, and "fixed" simply means that the price is fixed within a certain scope of risks and not subject to adjustment, and that the price still needs to be adjusted beyond such scope of risks.

Since there is no fixed-price contract in an absolute sense, it is unnecessary to distinguish fixed-price contracts from adjustable-price contracts, and it is sufficient to categorize contracts into unit price contracts and lump sum contracts.

Absolute fixed-price contracts are suitable for only a few projects that are characterized by small scales of construction, technical simplicity, and short construction periods. Under most circumstances, relative fixed-price contracts are the only choice; namely, the contract price is fixed and not subject to adjustment within the agreed scope.

\section{Lump Sum Contracts and Unit Price Contracts.}

What are the differences between lump sum contracts and unit price contracts? A unit price contract is a contract under which the unit prices are relatively fixed and not subject to adjustment within the agreed scope. A lump sum contract is a contract under which the total contract price is relatively fixed and not subject to adjustment within the agreed scope.

Where the unit price contract type is used, the bill of quantities is an integral part of contract documents, in which the quantities have contractual binding force, and project payments are adjusted based on the quantities of work actually completed when settled. Where the unit price contract type is used, if pricing is based on the bill of quantities, project payments shall be adjusted based on the quantities of work actually completed when settled; if a working drawing estimate is used, project payments shall be settled based on the quantities agreed in the contract and be not subject to adjustment except in case of any changes in work.

Is it appropriate to hold the bid inviter solely responsible for the accuracy of the bill of quantities included in a contract? Question: Article 4.1.2 of the 2013 Code of Pricing provides that the bill of quantities for bidding shall be used as an integral part of bidding documents, and that the bid inviter shall be held solely liable for its accuracy and integrity. Is this provision appropriate?

Analysis: Article 6.2.3 of the 2013 Code of Pricing provides that in bidding and bid activities, in case of any inconsistency between the characteristics described in the bill of quantities for bidding and the design drawings, a bidder shall determine the comprehensive unit price of its bid based on the characteristics of items described in the bill of quantities for bidding. Article 9.4.2 provides that in case of any inconsistency between construction drawings or design changes and the characteristics of items described in the bill of quantities, the employer and the contractor shall determine the comprehensive unit price in accordance with the contract based on the characteristics of the work actually completed.

The bill of quantities is above all as stipulated in the above Code of Pricing. However, Article 1.2 of Chapter 5 of the Standard Bidding Documents for Construction(2007) provides that the bill of quantities shall be read and understood together with the instructions to bidders, general conditions of contract, particular conditions of contract, technical preparations and requirements, and drawings 
contained in the bidding documents, and Article 2.2 provides that the unit prices or amounts ofthe successful bid for the bill of quantities shall cover the risks, liability, and obligations expressed or implied in the contract. Article 1.4 of Chapter 4 explains the priority of contract documents as follows: the Contract Agreement, the Letter of Acceptance, the Bid Letter and the Appendix thereto, the Particular Conditions of Contract, the General Conditions of Contract, the Technical Standards and Requirements, the Drawings, the Priced Bill of Quantities, and any other document forming part of the Contract.

The above bill of quantities code and contractual stipulation are contradictory. According to the theory that the bill of quantities is above all, the bill of quantities shall be placed first in the sequence, which is inconsistent with engineering and international practice. According to the contractual stipulation, the bid inviter is not liable for the accuracy of the bill of quantities, and the bidder shall read through the bidding documents. In case of any inconsistency between the bill of quantities and the bidding documents and design drawings, the bidder may either point out such inconsistency or understand according to the order of precedence of the contract documents, and it shall not consider the bill of quantities as a priority and think that the employer is liable for any inconsistency with the bill of quantities.

Are the unit prices under a unit price contract definitely binding? Case: A unit price contract is used for a project, and a bidder finally wins the bid at RMB 8.012 million. After winning the bid, the bidder discovers an arithmetic error. Is it allowed to correct the error and change the original price at which the bidder wins the bid? Namely, is RMB 8.012 million in the Table 1 allowed to be changed to RMB 8.12 million?

Table 1 The Price Scheme

\begin{tabular}{ccccc}
\hline Item & Quantity & Unit price & Total bid price & Total price corrected \\
\hline 1 & 1000 & 120 & 12,000 & 120,000 \\
Others & $\cdots$ & $\cdots$ & $8,000,000$ & $8,000,000$ \\
\hline
\end{tabular}

Analysis: The arithmetic error is not discovered during the evaluation of the bid, and may be corrected if discovered. However, since the bid is won at a price of RMB 8.012 million, such price is not allowed to be changed to RMB 8.12 million. The solution requires correcting unit prices, and the corrected unit prices multiplied by the quantities make the total bid price.

There are a lot of methods, one of which is as follows: Since the market price is RMB 120, the unit price RMB 120 is not allowed to be changed to RMB 12. A successful bid at a price of RMB 8.012 million indicates that RMB 8.012 million is higher than the cost. If the error was not made, the total bid price would be RMB 8.12 million. RMB 8.12 million - RMB 8.012 million = RMB 0.108 million, which may be construed as a loss of profit.It is assumed that construction estimating software works out a total profit of 1.08 million which is included in RMB 8.12 million. A total loss of profit would be $10 \%$, and each unit price could be deemed to suffer a $10 \%$ loss of profit. The costs of labor, materials, machines, and management involved in item (1) plus the profit equal RMB 120. Assuming that the labor, materials, machines, and management cost RMB 100, the profit would be RMB 20, and then RMB 18 after a loss of $10 \%$. The comprehensive unit price is adjusted from RMB 120 to RMB 118. The unit prices of other items are also adjusted in this way, and then all comprehensive unit prices will be adjusted. The adjusted comprehensive unit prices are not used to adjust the total bid price because the new comprehensive unit prices multiplied by the quantities equal the total bid price. They are used to determine how to settle the quantities beyond the scope of the bill. Therefore, RMB 8.012 million for the quantities in the scope of the bill remains unchanged, and the quantities beyond the scope of the bill will be settled at a new comprehensive unit price.

Although the unit prices under a unit price contract are binding, the total price is not allowed to be changed in the case of no change to the scope of the bill. Therefore, a unit price contract is, in essence, a lump sum contract within the scope of the bill. Not the unit prices under a unit price contract but the unit prices of the list consistent with the total price at which a bid is won is binding. 


\section{Application of the Price Types of Contracts.}

How to select the price types of contracts? Case: A government invests in a construction project. Due to various reasons, work is required to be commenced immediately. However, a preliminary design has just been created, and the project is not qualified for bidding at this moment. Upon special approval from the authorities, a unit price contract is used. The bidding documents only provide bidders with a schedule of items, the scope of the project and necessary descriptions, and estimated quantities. Bidders are only required to quote the unit prices of the items, and pricing in the future will be based on actual quantities.

Analysis: In this case, it is likely to finally find that the work actually done is inconsistent with the items contained in the list, and that the competitive unit prices are not suitable for final settlement and not binding. Therefore, for a project only with a preliminary design, the employer should commission the contractor to detail the design after providing a plan for the project, and then ask the contractor to estimate the quantities and total price based on the design detailed by it. In this case, a lump sum contract rather than a unit price contract is advised.

How to select the price types of contracts?

(1) If the items of a bill and their quantities are very exact, there will be a number of contract types available.

(2) If the items of a bill have been listed in detail and clearly, but there may be serious inconsistency between actual quantities and estimated quantities, a unit price contract is the most reasonable contract type, although it is unable to avoid bidders' unbalanced bids.

(3) If both the items of a bill and their quantities are unclear, a unit price contract will be inappropriate. Due to changes in items, the competitive unit prices will be inappropriate for settlement and useless. In this case, after providing a preliminary design, the employer may require the contractor to detail the design and quote its total price; namely, a lump sum contract is used.

How to avoid unbalanced bids? Question: For a contract in which pricing is based on the bill of quantities, since the quantities will be established based on reality, is it allowed to use estimated quantities when preparing a bill of quantities in order to save the employer's manpower input?

Analysis: A bidder will submit a strategic bid, namely an unbalanced bid, for the inaccurate quantities provided by the employer. It will place a high price on items whose actual quantities are expected to increase in the future, and a low price on items whose actual quantities are expected to decrease or remain unchanged in the future in order to maintain the overall cost unchanged and make it competitive. Therefore, if the quantities indicated in the list of quantities are inaccurate and estimated quantities are used, a bidder may submit an unbalanced bid.

If a contract in which pricing is based on the bill of quantities is used, a bidder may not point out the inaccurate quantities but may submit a strategic bid, namely unbalanced bid, for the inaccurate quantities. If the quantities provided in the list of quantities are very accurate, a bidder will be unable to use an unbalanced bid. However, if the quantities provided in the list of quantities are inaccurate, in order to prevent a bidder from using an unbalanced bid, a provision which prohibits the bidder from doing so should be included in the bidding documents, and a period of time should be given to the bidder to check the accuracy of the bill of quantities.

The scope of pricing for bidding should be analyzed. Question: If some items fail to be included in the list of quantities provided by a bid inviter (for example, the concrete floors, fences, and pools of some buildings at the construction site are not described in the drawings and bill of quantities but are defined in the scope of bidding in the "Instructions to Bidders"), should they be considered in a bid?

Analysis: To solve the above problem is actually to work out how to address the inconsistency between the scope of a bill and the scope of bidding. A bid actually corresponds to the scope of bidding (the scope of the contract). Therefore, the above items should be considered in a bid.

When a bid inviter provides a bill of quantities for Party B to bid for, the bid corresponds to the scope defined by the bidding documents, rather than the scope of the list or the scope of the drawings alone. Generally speaking, the scope of the list is smaller than the scope of the drawings, and the 
scope of the drawings is smaller than the scope of bidding (scope of the contract), as shown in Figure 1.

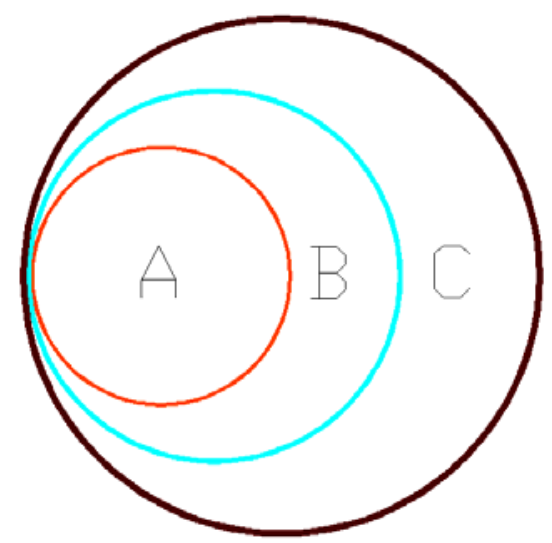

Fig. 1 Scope of pricing(A: Scope of the list, B: Scope of the drawingsC: Scope of the contract) When a bid inviter provides the bill of quantities, construction drawings, and a description of the scope of bidding in the bidding documents (the scope of the contract), a bidder should consider the scope of pricing based on the scope of bidding. It would be partial to consider that the scope of pricing is the scope of the bill of quantities. In the bid and bidding activities, a bid should be submitted based on the bill of quantities, and pricing should be based on the scope of bidding.

\section{Summary}

There is no fixed-price contract in an absolute sense, it is unnecessary to distinguish fixed-price contracts from adjustable-price contracts. Even if the unit prices under a unit price contract are binding, the total price is not allowed to be changed in the case of no change to the scope of the bill. Therefore, a unit price contract is, in essence, a lump sum contract within the scope of the bill. If the quantities provided in the list of quantities are inaccurate, in order to prevent a bidder from using an unbalanced bid, a provision which prohibits the bidder from doing so should be included in the bidding documents, and a period of time should be given to the bidder to check the accuracy of the bill of quantities. A bid inviter provides a bill of quantities for Party B to bid for, the bid corresponds to the scope defined by the bidding documents, rather than the scope of the list or the scope of the drawings alone. A bidder should consider the scope of pricing based on the scope of bidding. It would be partial to consider that the scope of pricing is the scope of the bill of quantities. In the bid and bidding activities, a bid should be submitted based on the bill of quantities, and pricing should be based on the scope of bidding.

\section{Acknowledgements}

This work was financially supported by the School-level Research Project of Beijing Vocational College of Agriculture(No. XY-BS-15-03).

\section{References}

[1] Model Text for Construction Contract for Construction Works(GF-2013-0201) [S]. China Architecture \& Building Press, Beijing, 2013;

[2] Coaching Textbook for Publicity and Implementation of Code of Pricing Based on Bills of Quantities of Construction Works(GB50500-2013). China Planning Press, Beijing, 2013;

[3] ZHAI Bowen, LIANG Chuan, ZHANG Junling, Study on mechanism of bid evaluation of hydropower project construction based on approximation ideal value, Journal of hydroelectric engineering. 4(2013) 246-251. 